Combination of Emoji And Text In Musicians' Twitter Posts

\author{
Yudha Nirmala
}

Universitas Sebelas Maret, Surakarta, Indonesia

\begin{abstract}
Author Note
Author is student of English Department, Faculty of Cultural Sciences, Universitas Sebelas Maret, Jalan Ir. Sutami 36A, Surakarta, Indonesia
\end{abstract}




\begin{abstract}
This research aims to understand the status relation and the way the text and emoji interacts in musicians' twitter posts. This research focuses on the musicians' twitter posts containing promotion, which also include emoji and text. This research design is a descriptive qualitative which uses the multimodality theory of the generalized image-text relation of Radan Martinec and Andrew Salway. Findings shows that the musicians tend to position the emoji subordinated to text. In terms of logico-semantic relation, the extension relation occurs more than the exemplification and enhancement relation. The emoji mostly provides additional information, which cannot be transferred within the text, such as expression and feeling. It is also used to symbolize the event they promote in the post, such as guitar emoji $(\&)$ in a concert promotion. The religious musicians tend to use emoji to provide information about themselves, such as feeling and expression. While, the rock musicians use the emoji more to put information about the event, such as the place and how many days left until the event begins.
\end{abstract}

Keywords: multimodality, image-text relation, emoji, text, musician. 


\section{Combination of Emoji And Text In Musicians’ Twitter Posts}

One aspect of human life, which has changed drastically since the invention of internet, is communication. Social media is the most significant result of internet's development. Because of its wide impacts, Cotter (2015) has suggested social media as the "prime players on the cultural stage".

Nevertheless, the early version of online communication was lack of the ability to deliver non-verbal element of communication, such as expression and tone. It only provided the facility to deliver textual message. Furthermore, considering that only seven percent of communication was verbal (Mebrabrian, 1971), non-verbal elements should be delivered effectively in having an effective communication. In order to overcome the loss, people can use pictographic elements, such as emoticon and emoji. Pictographic elements are important for compensating for the loss of auditory and visual information in texting with e-mail. (Provine, Spencer \& Mandell, 2007).

In 2015, the Oxford Dictionary declared a statement that its word of the year was "Face with Tears of Joy" emoji, which was actually a pictograph. Oxford Dictionary also stated that this emoji has the percentage of 20 percent of all emoji used in Britain in 2015, and 17 percent of all emoji used in the United States (''Face with tears of joy' emoji”, 2016). This occurrence indicates that emoji is getting more comprehension from the online media users and becoming an important element of modern communication.

Some researches have been conducted regarding to the emotion through online media. For example, the management of laughter in WhatsApp (Petijean \& Morel: 2017) and the placements of punctuation and emoticons in a clause (Provine, Spencer \& Mandell: 2007). Both researches mainly focused on the placement and the quantity of the emotional expressions. Although, Petijean \& Morel (2017) also described the orient of having laughter on the chat, they used only textual 
laughter, excluding both emoji and emoticon. Moreover, those researches applied quantitative method.

The combination textual message and visual emotion in online communication and its role in online conversation have also been discussed in some focuses, such as, social motives and social context effects on interpretations of emoticon (Derks, Bos \& Grumbwok: 2008), and empirical impacts (Walther \& D’Addario: 2001). While, some researchers used semantical approach (Ai, Lu, Liu, Wang, Huang \& Mei: 2017; Wijeratne, Sheth, Balasuriya \& Doran: 2017) and sentiment analysis (Wolny: 2016). The combination of semantic and sentiment approach on analyzing interpretations on emoji has been done by Miller, Spieker, Chang, Johnson, Terveen and Hect (2016). Those researches discussed mainly on the structure of the clause along with emoticons and how the emoticons affect the reader's understanding on the messages. Although Wolf (2000) succeeded to see how gender can affect emoji usage, again, he focused more on the amount of emoji usage. However, there have not been many researches conducted to analyze combination of emoji and text to see how emoji and text works together as a form communication between musicians and their fans employing Systemic Functional-Multimodal Discourse Analysis (SFMDA).

This research tries to analyze how emoji and text works together in the process of meaning making. It uses some twitter posts of some musicians of two genres and see how they combine emoji and text. As for the context of the post, promotion is chosen. To reveal how each musicians of each genre combine emoji and text in doing the promotion based on their music genre on twitter with the text, Martinec \& Salaway's generalized image-text relation system is used. This system can be used to describe relations where the image serves the text, where the text serves the image, 
and where image and text are equally dependent or independent of each other (Kornalijnslijper, 2014). 
Method

This research design is a descriptive qualitative research to examine any symbolic messages of texts or discourses of musicians' emoji embedded posts in twitter, which contain elements of promotion. Its goal is to describe how image and text are combined in the musicians' posts in twitter which drives the understanding of relation between emoji and text and how they serves each other. This research also purposes to understand the phenomena of what is experienced by subjects such as behavior, perception, motivation, action, etc. (Moleong, 2007).

The source of the data is the twitter account of Maher Zain, Sami Yusuf and Harris J representing religious musician and the rock genre musicians of Metallica, Gorillaz, and Bon Jovi. The data are collected from taking posts from several twitter accounts. Since this research studies the combination of emoji and text, the posts taken should contain emoji and text.

The primary data contain the realization of image and text relation in musicians' posts by image-text study. This involves the analysis of image-text relations, which involves the logicosemantic relation and status relation between image and text. The analysis of image-text relation is used to figure out how each modes serves each other and how they are linked. The analysis employs Radan Martinec and Andrew Salway's generalized image-text relation. The first relation analyzed is the status relation between emoji and text. The status relation is analyzed with considering the level of equality between image and text. In the logico-semantic relations, clauses are related through either expansion or projection. In expansion, one mode develops or extends the meaning of the other mode. Projection is on the two different contexts, such as comic book and a combination of diagrams and text (Kornalijnslijper, 2007). 


\section{Findings \& Discussion}

There are two different groups of musicians whose twitter accounts are chosen as the sources of data. The first group of musicians are Maher Zain, Harris J and Sami Yusuf as the representation of religious genre musicians. The second group of musicians are Metallica, Gorillaz and Bon Jovi as the representation of rock genre musicians. In order to find the image-text relation between the text and emoji, status relation and logico-semantic relation analysis are used. Status relation is divided into two types: equal and unequal. Then, equal relation has two kinds of relation: independent and complementary, while unequal relation is divided into two categorizations: image subordinate to text and text subordinate to image. As well as in Halliday's clause complex system, the logico-semantic relation is divided into expansion and projection. Expansion relation consists of elaboration, extension and enhancement. Projection includes idea and locution.

In terms of logico-semantic relation forty-six data are identified as elaboration, fifteen data belong to enhancement and there are seventy-one data are considered as extension. It shows that extension has the biggest number comparing to the other relation. Yet, it actually does not occur in the musicians who belong to the rock genre. Their posts mostly belong to elaboration, exemplification relation. Thus, they tend to use emoji to give more general information about the text. The most infrequent appearance of the relation between the text and emoji in this research is enhancement. The other main relation of logico-semantic, locution, does not appear in this research.

In terms of status relation, there three relation appeared. These relations are complementary, image subordinate to text and independent. The most dominating relation is image subordinate to text with ninety-four appearances. Complementary relation appears twenty times and the independent relation appears eighty times. 
Table 1 Use of Text and Emoji Combination by the Musicians

\begin{tabular}{|c|c|c|c|c|c|c|c|c|c|c|c|c|}
\hline \multirow{4}{*}{$\begin{array}{l}\text { Music } \\
\text { Genre }\end{array}$} & \multirow[t]{4}{*}{ Accounts } & \multicolumn{2}{|c|}{ Status } & \multicolumn{8}{|c|}{ Logico-Semantic Relation } & \multirow[t]{4}{*}{$\Sigma$} \\
\hline & & & & \multicolumn{6}{|c|}{ Expansion } & \multicolumn{2}{|c|}{ Projection } & \\
\hline & & & & \multicolumn{2}{|c|}{ Elab } & \multicolumn{3}{|c|}{ Enh } & \multirow[t]{2}{*}{ Ext } & \multirow[t]{2}{*}{ Loc } & \multirow[t]{2}{*}{ Id } & \\
\hline & & & & Exemp & Expo & $\mathrm{T}$ & $\operatorname{Pr}$ & $\mathrm{Pl}$ & & & & \\
\hline \multirow[t]{12}{*}{ Religious } & Maher Zain & $\mathrm{Eq}$ & Ind & - & - & - & - & - & - & - & - & - \\
\hline & & & Com & - & - & - & - & 2 & - & - & - & 2 \\
\hline & & Un & IST & - & 1 & - & - & - & 14 & - & - & 15 \\
\hline & & eq & TSI & - & - & - & - & - & - & - & - & - \\
\hline & Harris J & $\mathrm{Eq}$ & Ind & - & - & - & - & - & - & - & - & - \\
\hline & & & Com & - & - & - & - & - & - & - & - & - \\
\hline & & Un & IST & 2 & - & - & - & - & 22 & - & - & 24 \\
\hline & & eq & TSI & - & - & - & - & - & - & - & - & - \\
\hline & Sami Yusuf & $\mathrm{Eq}$ & Ind & - & - & - & - & - & - & - & - & - \\
\hline & & & Com & 7 & - & - & 1 & 1 & - & - & - & 9 \\
\hline & & Un & IST & 1 & 2 & - & - & - & 20 & - & - & 23 \\
\hline & & eq & TSI & - & - & - & - & - & - & - & - & - \\
\hline \multirow[t]{7}{*}{ Rock } & Metallica & $\mathrm{Eq}$ & Ind & 2 & 1 & - & - & - & 1 & - & - & 4 \\
\hline & & & Com & - & - & - & - & - & - & - & - & - \\
\hline & & Un & IST & 11 & 1 & - & - & - & 1 & - & - & 13 \\
\hline & & eq & TSI & - & - & - & - & - & - & - & - & - \\
\hline & Gorillaz & $\mathrm{Eq}$ & Ind & 8 & - & - & - & - & - & - & - & 8 \\
\hline & & & Com & - & - & 3 & - & 6 & - & - & - & 9 \\
\hline & & & IST & - & - & 1 & - & 1 & 8 & - & - & 10 \\
\hline
\end{tabular}




\section{Un}

eq

Bon Jovi $\quad \mathrm{Eq}$

Un

eq

$\Sigma$

\section{A. Unequal Status in Emoji-Text Relations}

In Martinec's \& Salway's (2005) classification of status relation, the unequal status is divided into two categories, it can be either "image subordinate to text" relation, or "text subordinate to image".

\section{Image Subordinate to Text}

The table 1 shows that "image subordinate to text" has the dominant proportion. There are ninety-four emoji-text relations are defined as "image subordinate to text". An image is defined as subordination of the text when it is not related to the whole text, but only a part of the text (Martinec \& Salway, 2005, p. 348). The figure 1 below is an example of unequal relationship, which was taken from Metallica's twitter post: 


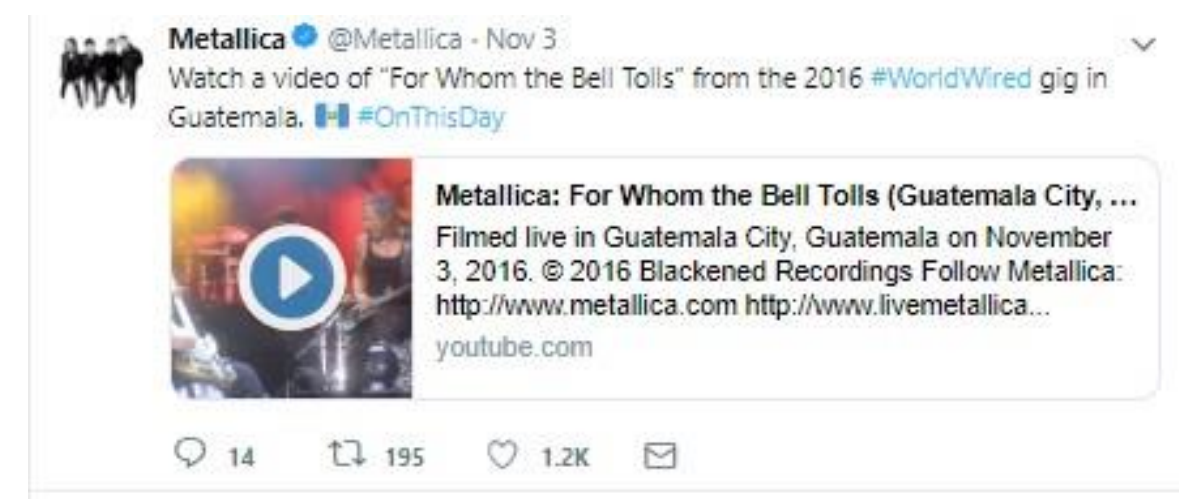

Figure 1: Example of "image subordinate to text" from Metallica's post

This post is published in order to share a video of one of Metallica's performance in Guatmela, Argentina. The song Metallica performed is entitled "For Whom the Bell Tolls". They use "Watch" word to persuade their followers to watch the video. They also put an Argentina flag emoji ( $)$ at the end of the post to underline Guatemala, which is one of cities in Argentina. Therefore, the relatedness of the emoji to only a part of the text is the indication of image subordination to the text.

\section{Text Subordinate to Image}

"Text subordinate to image" is another type of unequal status in image-text relations. The realization to define an image as subordinate to text is when there is an "implicit devices that need to be decoded by reference to an image" (Martinec \& Salway, 2005, p. 347). The table 1 shows that there is no "text subordinate to image" relation found in this research.

\section{B. Equal Status in Emoji-Text Relations}

Martinec's \& Salway's (2005) classify the equal status into two categories, it can be either "independent" relation, or "complementary" one.

\section{Image \& Text Independent}

From Table 1, we can see that there are eighteen "image and text independent" relations in the posts. Moreover, this relation only appear in rock musicians' posts. A relation between image 
and text is defined as "image \& text independent" when the image and the text are related dependent or independent of each other (Kornalijnslijper, 2014).

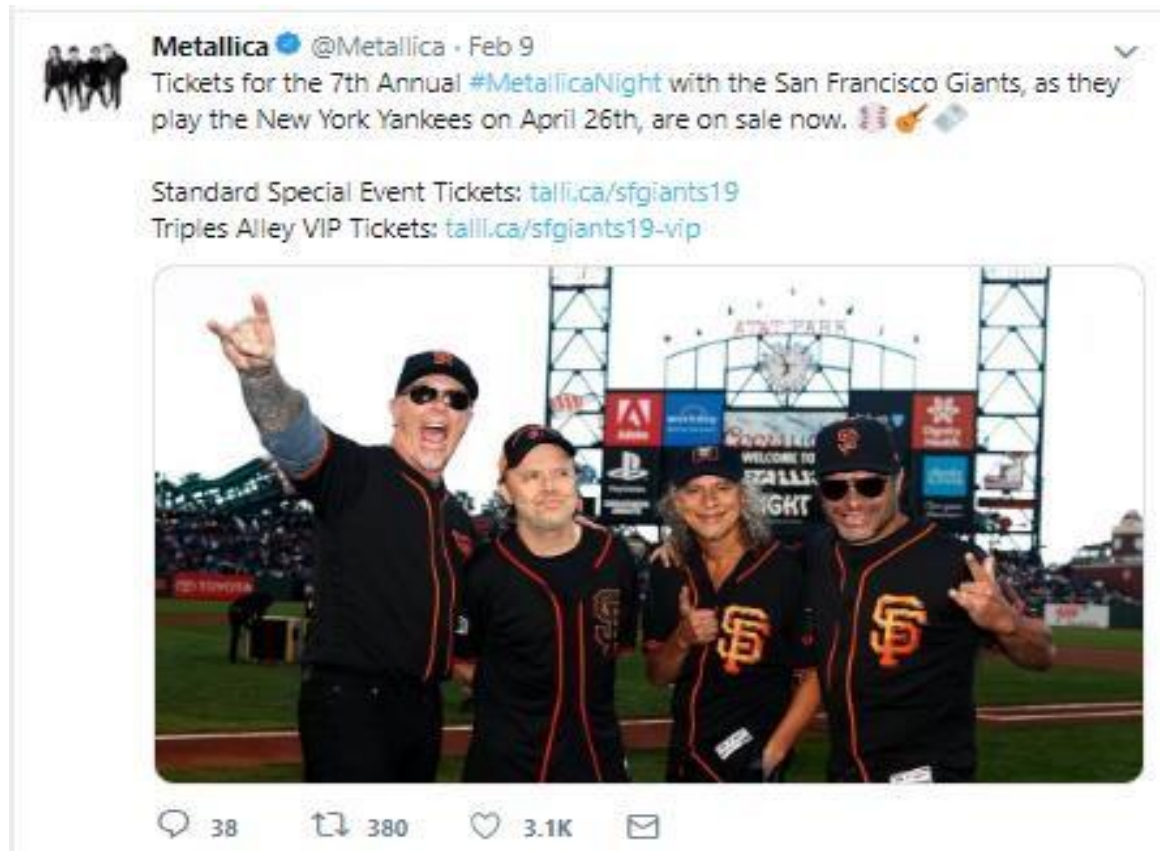

Figure 2: Example of "image subordinate to text" from Metallica's post

The relation status between the text and the emoji is equal, independent as the emojis are related to whole text and they have no function on modifying the meaning of text. The sequence of guitar emoji (\&), baseball emoji ( ) and ticket emoji ( ) stands only as a simple representation of the annual, the location and the date of the event.

\section{Image \& Text Complementary}

The another kind of equal status in image-text relation is "image \& complementary". Table 1 displays that there are twenty "image \& complementary" in musicians' twitter posts. One imagetext relation can be said as "image \& text complementary" when the image and text are combined to form a bigger syntagm (Martinec \& Salway, 2005). The musicians position the emoji to work together with the text to create message. The emoji and the text complement each other, thus, in order to deliver the message, emoji and text cannot be separated. This relation appears usually 
when the musicians talks about a link of a website and some parts of their song lyrics. An example of this relation is the figure 3 below.

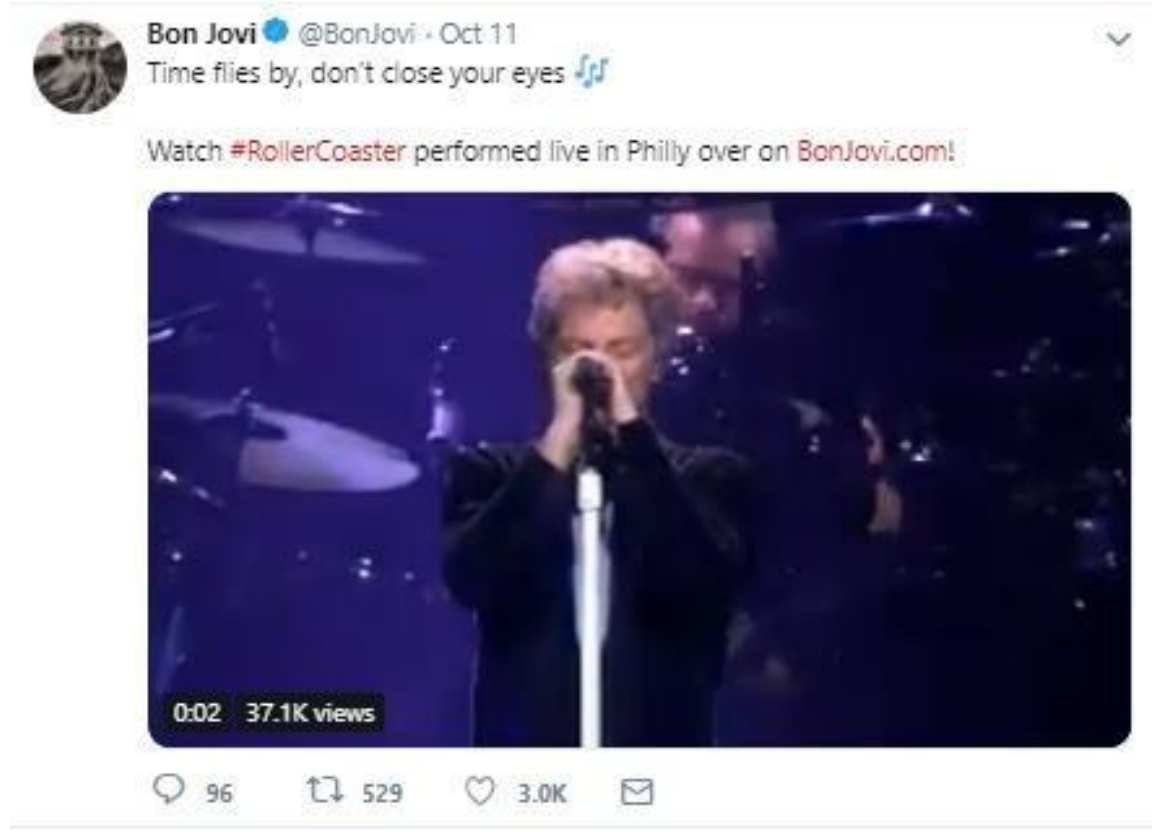

Figure 3: Example of “image \& text complementary” from Bon Jovi”s post

Bon Jovi shared a video of their music concert. The song they were playing was represented by the lyric asserted, “Time flies by, don't close your eyes", which was a part of the song entitled "Roller Coaster". Bon Jovi also told their followers to watch their music video through the link they put in the post. At the end of the lyric, they put a musical notes emoji (

The emoji is related to the lyric of the song. The musical notes emoji ( لّ") indicates that the text is actually a part of a song lyric. It provides new information about the text. However, without the emoji, it is rather difficult to understand that the text is a song lyric. The combination of the emoji and the text are meant to create a bigger syntagm than just emoji or text alone.

\section{Elaboration in Logical-semantic Image-text Relations}

Elaboration includes exposition and exemplification. The categorization of elaboration depends on the comparison of generality between image and text. If image and text are different 
on generality, the image-text relation is exemplification, either 'text more general' or 'image more general'. The amount of data of the elaboration relation of emoji and text is forty-six. In general, the musicians, who have this kind of relation, use emoji to give more detailed or general information about the text, such as a national flag in representing a city in that country and camera emoji (영) for a concert video.

\section{Exposition}

When image and text are on the same level of generality, the image-text relation is exposition. The table 1 displays that there are seven image-text relations defined as exposition. Therefore, as exposition demands same level of generality, the status relation of the image and text is usually equal. One example of exposition is the figure 4 below. 


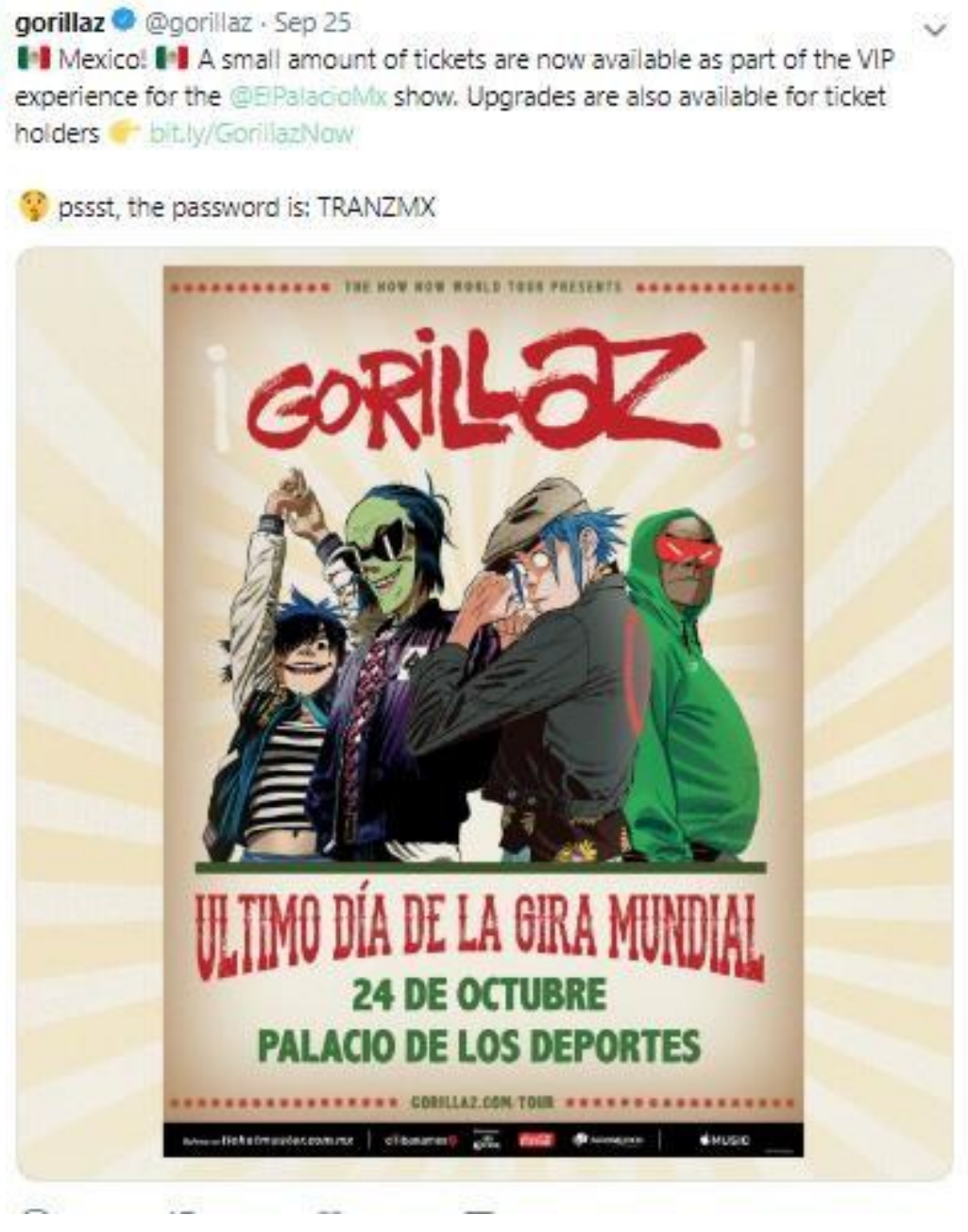

Figure 4. Example of “image \& text exposition” from Gorillaz's post

In this post, Gorillaz offered some VIP tickets for the El Palacio Mx show at Mexico. They also added an information about a benefit that the VIP ticket holders would have. At the end of the post, they put the link to the benefit and the password. The logico-semantic relation analysis in this post is only applied on the Mexican flag Emoji (1) and the word "Mexico" at the beginning of the post. The rest of the post is excluded from the analysis as they have different logico-semantic relation. The Mexican flag emoji (1) stands as a signification of the "Mexico" word and does not provide further information about the word. Nevertheless, the generality level between the Mexican flag emoji (1) and the word are in the same level. Therefore, the logico-semantic relation 
between the Mexican flag Emoji (IN) and the word "Mexico" is considered as elaboration, exposition.

\section{Exemplification}

The other image-text relation that are comprised in elaboration. Exemplification is defined as an image-text relation that positions image and text in different level of generality. As what table 1 display, there are thirty-nine image-text relations classified as exemplification, either "image more general" or "text more general".

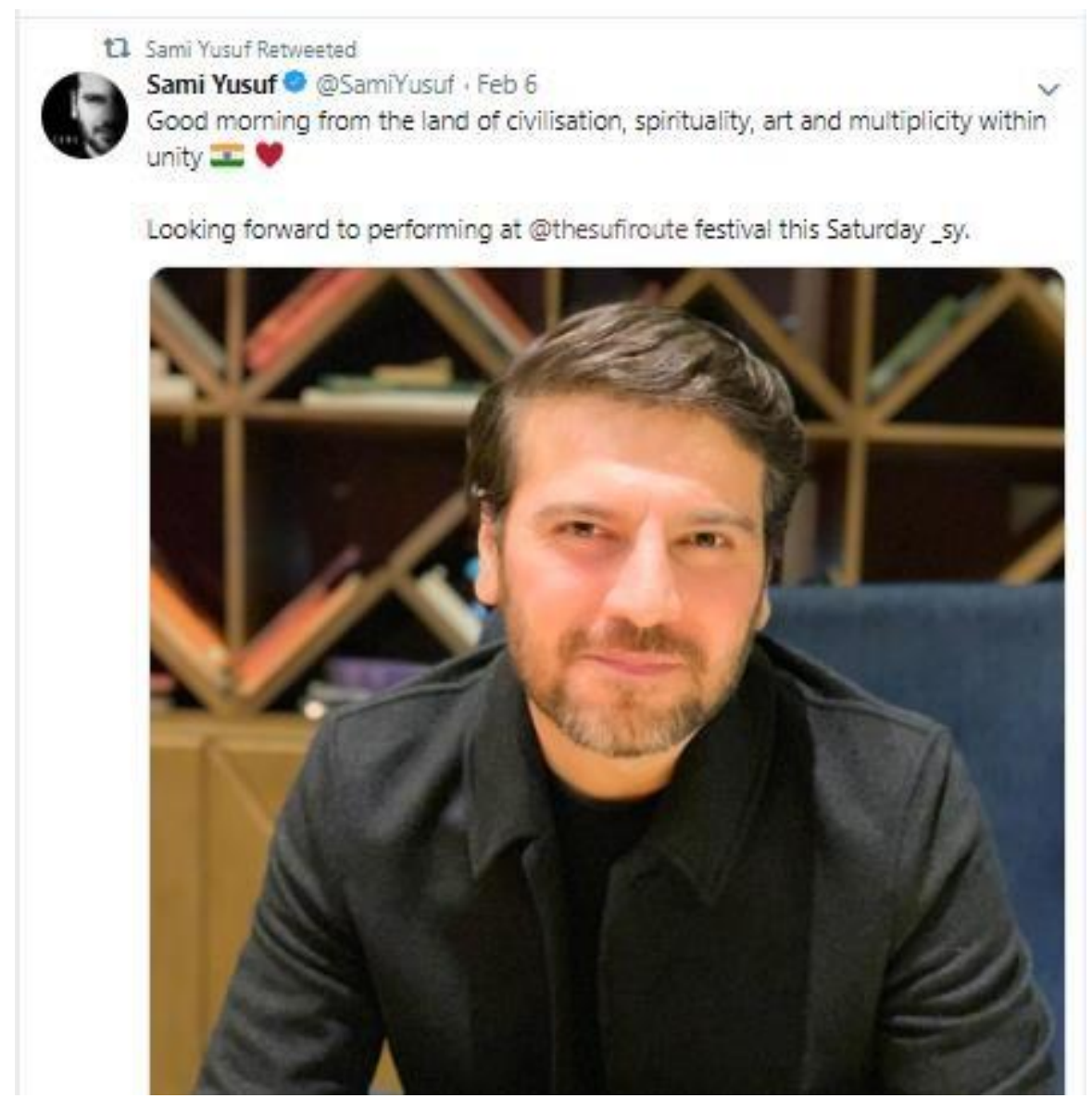

Figure 5. Example of “image \& text exemplification” from Sami Yusuf”s post

In this post, Sami Yusuf told his followers that he was in India. He puts a line, which says "the land of civilization, spirituality, art and multiplicity within unity" to represent India, whose flag is positioned at the end of the sentence. He also added a heart emoji after the India flag emoji 
(2) Sami Yusuf, according to his statement at the second part of the post, was in India to perform at The Sufi Route Festival.

The India flag emoji $\rightarrow$ in this post works to show Sami Yusuf's location at that time. The emoji is only related to the line representing India. However, the line that says "the land of civilization, spirituality, art and multiplicity within unity" is less general than the India flag emoji, which means that the emoji and the text are in different level of generalization. Therefore, the relation between the India flag emoji $(\theta)$ and the metaphorical expression it is related to is considered as elaboration, exemplification.

The independent relation usually appears when the musicians give a symbolization of one part of the message. For example, a ticket emoji ( ) is used to symbolize the ticketing process and fallen leaf emoji is used to represent autumn event. The emoji and text do not relate each other to create meaning.

\section{Enhancement in Logical-semantic Image-text Relations}

The enhancement relation has the smallest number of occurrence in this research. The amount of this relation is fifteen data in total. The relation that appears the most of enhancement relation type is enhancement of place, which has ten data representing it. The second relation is the enhancement of time with four data and the last is the enhancement of purpose/reason with one data appears. Enhancement can be defined as an image-text relation in which "one mode enhances the other mode by referencing it with circumstantial information like a time, a place, a reason, and a purpose” (Martinec \& Salway, 2005, pp.350-351).

\section{Enhancement: place}

The table 1 indicates that there are ten "enhancement: place". The place enhancement is mostly appears in the form of a combination of pointing right hand emoji ( ) and a link of a 
website. This emoji is usually used to show the location of the link of a video. However, a link of a video is actually arranged in a form of combination of some letters that is difficult to understand if it is presented without any clue, such as color of the letters and emoji. Furthermore, place enhancement relation sometime also appears in different kind of combination. The musicians sometime use national flag emoji to tell their followers about the location they are going to visit.

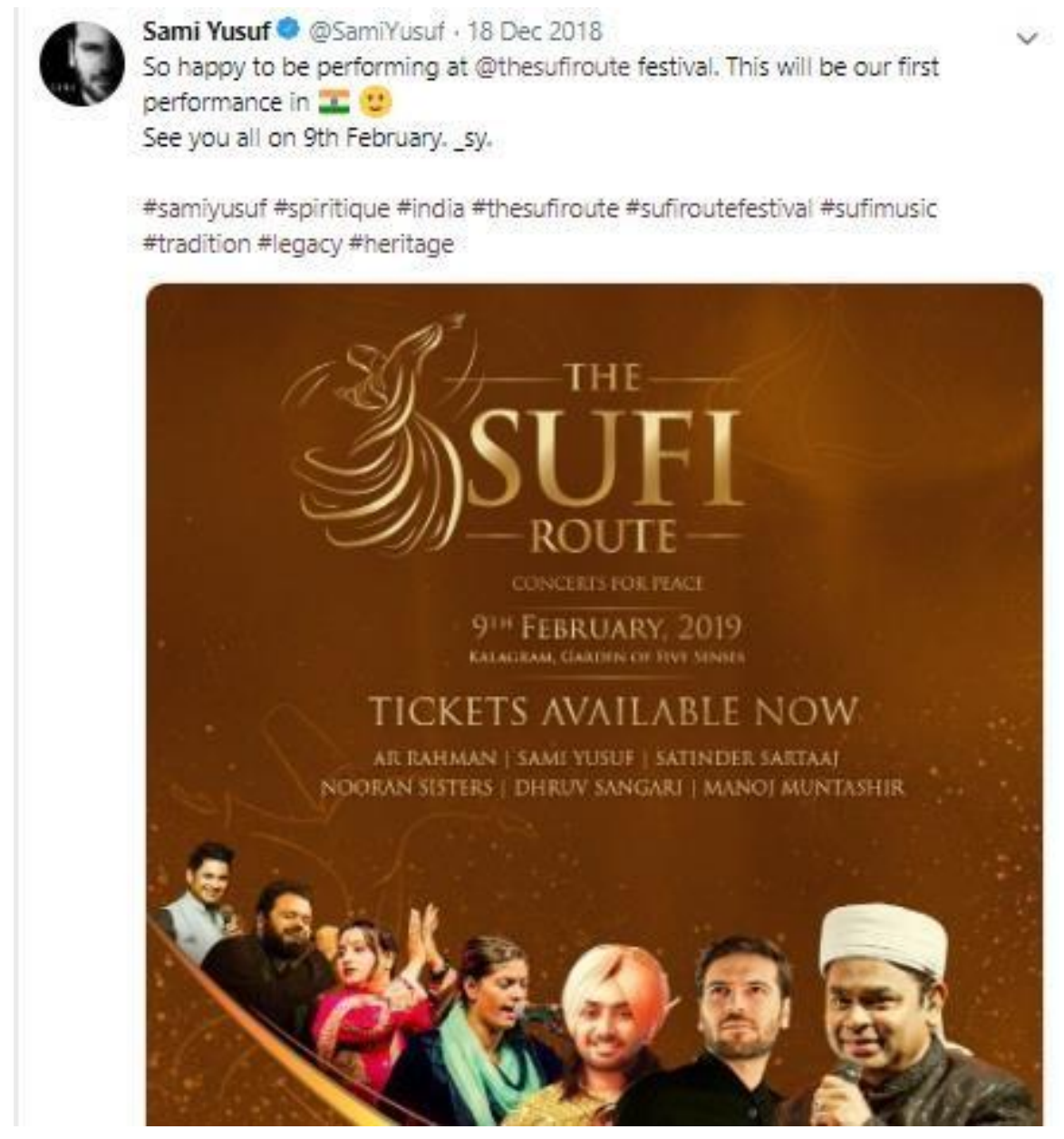

Figure 6. Example of “enhancement: place” from Sami Yusuf”s post

Sami Yusuf made a post about his upcoming perform at "The Sufi Route" on 9 February 2019. He added India flag emoji $\stackrel{\odot}{\hookrightarrow}$ to show the location and smile emoji $(*)$ to represent his feeling. In this post he put two emojis, India national flag $(\odot)$ and smile emoji. The logicosemantic relation between the India flag emoji ( $)$ and the text is considered as enhancement, 
place. The India flag emoji $(\odot)$, however, provides an information that is unavailable in the text, which is the location where the Sufi Route concert is going to be held. Therefore, the image-text relation is "enhancement: place".

\section{Enhancement: time}

There are four image-text relations that is included into "enhancement: time". The combination of emoji and text, which is included in this type of enhancement, usually appears when the emoji is used to give information about the days left to a concert. It is used as a replacement of the real number as it appears in the form of numeric emoji, such as "4" emoji (4 ) .

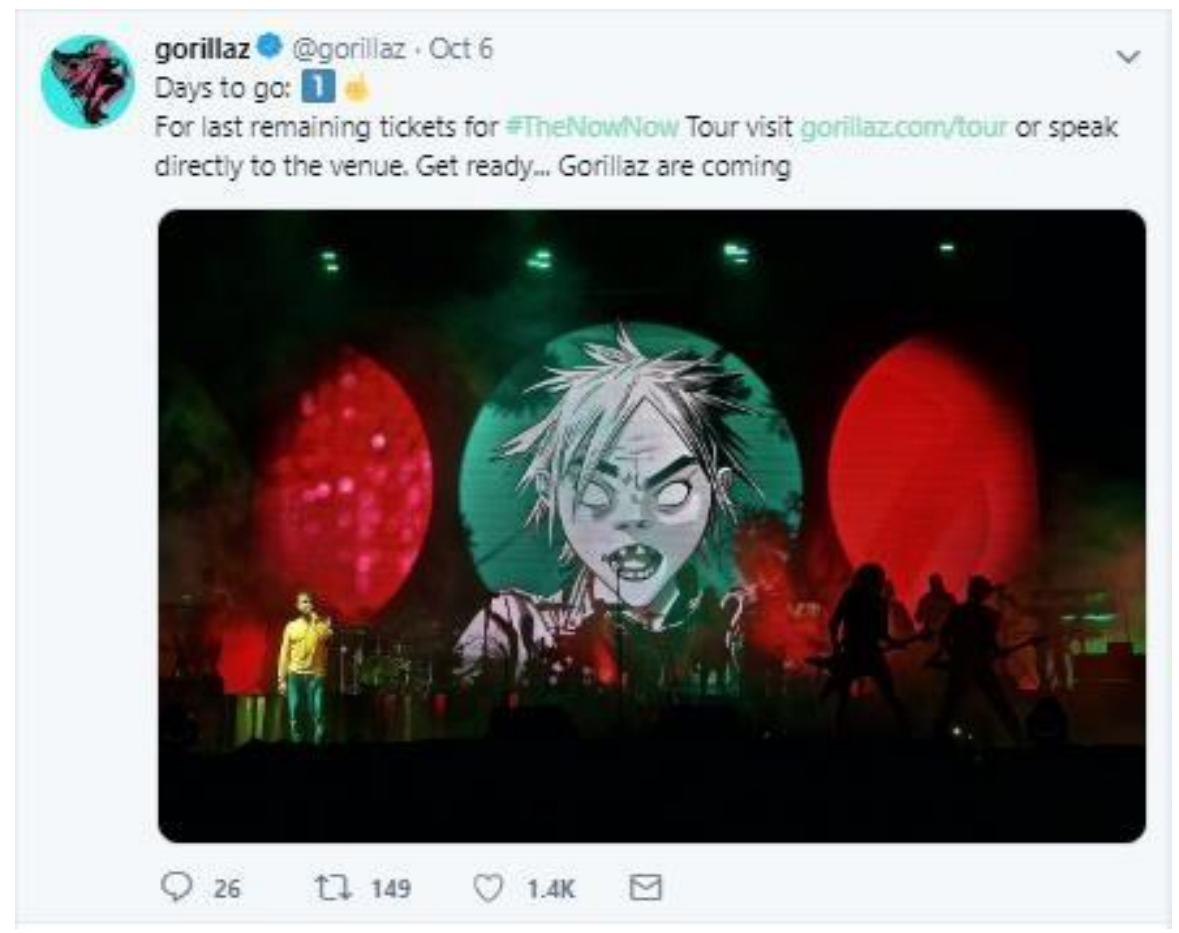

Figure 7. Example of “enhancement: time” from Gorillaz’s post

In this post, Gorillaz reminded their fans about "The Now Now Tour". This post was published to advertise the event. They put the link to get the ticket of the tour at the second part of 
the post. One emoji ( 1 ) and pointing up emoji $(\circlearrowleft)$ was also used in this post. They were positioned at the beginning of the first part of the post, which was used to tell the day left. Therefore, the logico-semantic relation between the text and the emojiwais considered as enhancement, time.

\section{Enhancement: causal (reason/purpose)}

The table 1 displays that there is only one image-text relation categorized as "enhancement: causal (reason/purpose)". Figure 8 demonstrates the image-text relation of "enhancement: causal (reason/purpose)" which is extracted from one of Sami Yusuf's twitter posts.

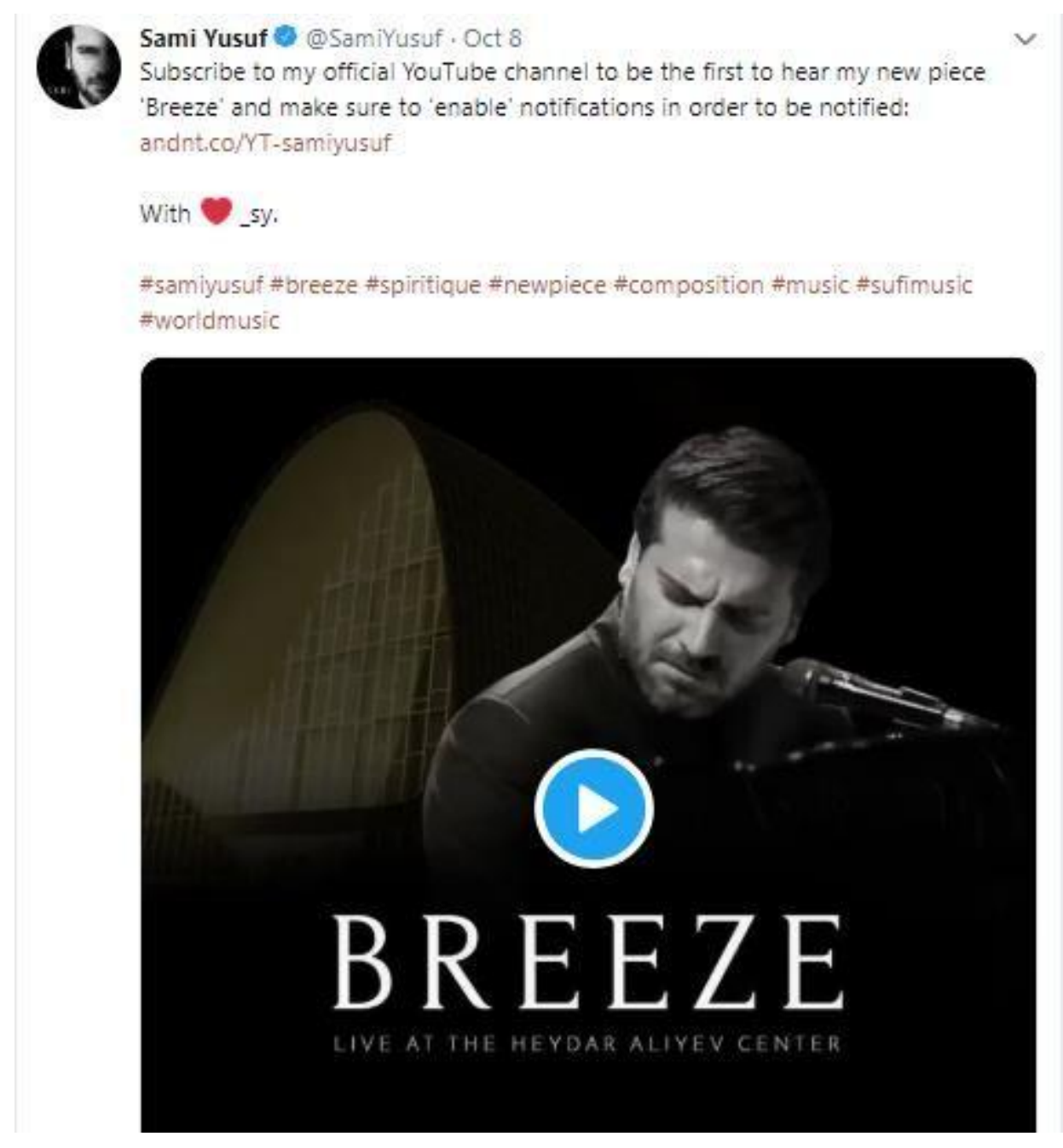

Figure 8. Example of “enhancement: casual (reason/purpose)” from Sami Yusuf's post 
In this post, Sami Yusuf persuaded his followers to subscribe his official YouTube channel. He enticed his followers by saying that they were be able to hear his new piece entitled "Breeze" if they subscribed his channel. He also added heart emoji $(\theta)$ at the end of the post to show his love to his fans.

The heart emoji (Q), in this post, is related to the whole post. It provides an additional information about the condition of Sami Yusuf when he published the post in Twitter, which is with love. Hence, the logico-semantic relation between the heart emoji $(\Omega$ ) and the text it is related is considered as enhancement, reason/purpose.

\section{E. Extension in Logical-semantic Image-text Relation}

From the table 1 , we can see that the highest number of the frequency of the logicosemantic relation of text-emoji combination is extension. An image text relation can be defined as extension when "one mode extends or adds new information to the other mode, because it goes beyond what is represented in the image, and beyond its participants, processes, and circumstances" (Martinec \& Salway, 2005, p.350). There are fifty-six data classified as extension. The musicians usually use emoji to provide information about the tone of the text.

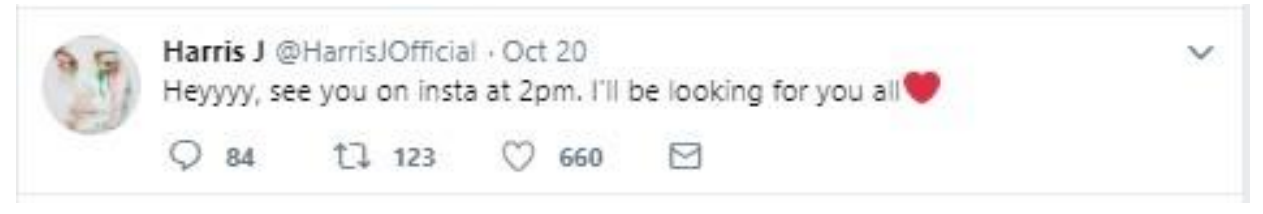

Figure 9. Example of “extension” from Harris J's post

Harris $\mathbf{J}$ would have a video of his raw cover record on his Instagram story at 2 p.m. that day. He asked his followers to visit his Instagram account at that time. At the end of the post, he pus a heart emoji ( ). 
The heart emoji stands as a symbolization of his feeling to his fans. It shows that Harris $\mathbf{J}$ love his fans. This message actually is not delivered by the text, which means that the emoji gives new information beyond the text. Thus, the logico-semantic relation between the text and the heart emoji ( ) is assessed as extension.

\section{Conclusion}

The result of the research shows that unequal relation status and image subordinate to text has biggest number of appearance, while the equal independence has the smallest frequency of appearance. This indication shows that the musicians from both genre of music, religious and rock, mostly use emoji as modifier of the text. Therefore, the text works as the main element of the posts.

This finding also shows that textual communication still dominates the social media. Although generally, having only textual communication cannot deliver message as good as multimodal communication, it is still considered as the simplest and easiest way to communicate to each other with place and time boundaries. However, emoji helps people to have better online communication as it can fulfill the non-verbal element missed in textual communication.

In this research, logico-semantic relation is used to analyze how image and text serve each other in musicians' promotion twitter post. The result is that the emoji can be combined with text to provide addition information that cannot be delivered by having only textual message. The most common use of emoji is complementing text with non-verbal element, such as facial expression and tone. Some kinds of emoji can be also used to show the feeling of the sender, such as heart emoji ( ), which represents love or excitement.

There are differences between rock and religious musicians on combining emoji and text. The rock musicians mostly to provide information about the event they post, such as place, time 
and some symbolizations about the event. Moreover, their use of emoji is also more varied than the religious musicians. For example, when they promote one of their live concerts, they usually put national flag emoji to represent the place they are going to be, numeric emoji in order to remind their followers about the days left until the concert start or some things that works as a symbolization of the event, such as guitar ( $\&$ ) and ticket emojis ( ). While, the religious musicians tend to use emoji to express their feeling, thus they use smileys more than any kind of emoji. This kind of combination can be suggested as a way to make their posts look friendly and welcoming (Burge, 2017). This pattern is applied not only for promotion post, but also for any kind of post they have.

In terms of status relation, they tend to position emoji in subordinate position to the text. However, the musicians still consider that text cannot be replaced to deliver message through social media as the text can deliver specific message, such as the exact location and time of an event (Kress, 2010). Thus, text is still considered as the most effective way to communicate through social media, although the other communication element, such as expression and tone, cannot be delivered efficiently only by having text.

On the other hand, emoji also has important position on social media, such as adding joy element on the text and providing information about expression and feeling of the musicians. Therefore, the musicians still use the emoji along with the text in order to look friendly by avoiding having dry message (Burge, 2017) and highlight some points on their posts, which need more attention. 


\section{References}

Ai, W., Lu, X., Liu, X., Wang, N., Huang, G., \& Mei, Q. (2017). Untangling Emoji Popularity Through Semantic Embeddings. In International AAAI Conference on Web and Social Media. Retrieved from https://www.aaai.org/ocs/index.php/ICWSM/ICWSM17/paper/view/15705/14788

Burge, J. (2017, April 10). How emoji replaced QWERTY as the world's most popular keyboard

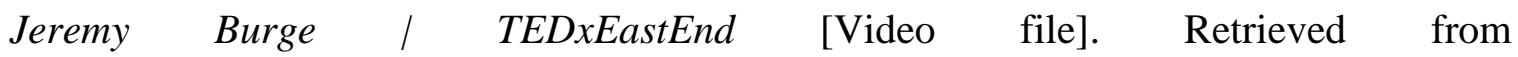
https://www.youtube.com/watch?v=bsZBziJVzNA.

Cotter, C. (2015). Discourse and media. In D. Tannen, H. E. Hamilton \& D. Schiffrin (Ed.), The handbook of discourse analysis (pp.795-821). Oxford, UK: Wiley-Blackwell. doi: 10.1002/9781118584194.ch37

Derks, D., Bos, A. E. R., \& Grumbkow, J. (2008). Emoticons and online message interpretation. Social Science Computer Review, 26(3), 379-388. Sage Publications. doi: $10.1177 / 0894439307311611$

'Face with tears of joy' emoji engulfs social media in 2015. (2016, January 04). Retrieved from http://www.chinadaily.com.cn/culture/2016-01/04/content_22925454.htm

Kress, G. (2010). Multimodality: A social semiotic approach to contemporary communication. New York: Routledge.

Kornalijnslijper, D. S. (2007). A study of three models for image-text relations. Retrieved from http://citeseerx.ist.psu.edu/viewdoc/citations;jsessionid=FEAF72653C186C2111CB97C D6C4F4446?doi=10.1.1.407.871 
Martinec, R., \& Salway, A. (2005). A system for image-text relations in new (and old) media. Visual Communication, 4(3), 337-371. Sage Publications. doi: $10.1177 / 1470357205055928$

Mehrabian, A. (1971). Silent messages. Belmont, CA: Wadsworth.

Miller, H., Spieker, J.T., Chang. S., Johnson. I., Terveen, L., \& Hect, B. (2016). “Blissfully Happy” or "Ready to Fight": Varying Interpretations of Emoji. HERMES - Journal of Language and Communication in Business, (55), 11-25. https://doi.org/10.7146/hjlcb.v0i55.24286

Moleong, L. J. (2007). Metodologi penelitian kualitatif. Bandung: Penerbit PT Remaja Rosdakarya Offset.

Pavalanathan, U., \& Einstein, J. (2015). Emoticons vs emojis on twitter: a causal inference approach. ArXiv. Atlanta, GA. Retrieved from https://arxiv.org/abs/1510.08480

Petitjean, C., \& Morel, E. (2017). "Hahaha": Laughter as a resource to manage WhatsApp conversations. Journal of Pragmatics, 110, 1-19. doi: 10.1016/j.pragma.2017.01.001

Provine, R. R., Spencer, R. J., \& Mandell, D. L. (2007). Emotional expression online: Emoticons punctuate website text messages. Journal of Language and Social Psychology, 26(3), 299_ 307. doi: $10.1177 / 0261927 \times 06303481$

Sanderson, D. W. (1993). Smileys. Sebastopol, CA: O’Reilly Media.

Wijeratne, S., Sheth, A., Balasuriya, L., \& Doran, D. (2017). A Semantics-Based Measure of Emoji Similarity. ArXiv. Atlanta, GA. Retrieved from https://arxiv.org/abs/1707.04653

Wolny, W. (2016). Twitter Sentiment Analysis Using Emoticons and Emoji Ideograms. Studia Ekonomiczne, 296, 163-171. Retrieved from http://cejsh.icm.edu.pl/cejsh/element/bwmeta1.element.cejsh-74a49185-95f0-4712-a09fced5bf5477f1 
Xie, B. (2008). Multimodal computer-mediated communication and social support among older Chinese internet users. Journal of Computer-Mediated Communication, 13, 728-750. doi:10.1111/j.1083-6101.2008.00417.x 